\title{
Association Between Maternal HIV Stigma Among South Indian Mothers Living with HIV and the CD4 Count of Children Living with HIV
}

\author{
Valerie PhamDo ${ }^{1}$ (1) Adeline M. Nyamathi ${ }^{1} \cdot$ Maria L. Ekstrand ${ }^{2,3} \cdot$ Sanjeev Sinha ${ }^{4} \cdot$ Kartik Yadav $^{1} \cdot$ Sanghyuk S. Shin $^{1}$
}

Accepted: 13 November 2021 / Published online: 11 December 2021

(c) The Author(s) 2021

\begin{abstract}
HIV stigma takes a multidimensional toll on a mother's ability to care for herself and subsequently may impact her ability to care for her child, particularly when mother and child are seroconcordant. A cross-sectional analysis was conducted to examine the association between maternal HIV stigma and child CD4 count in rural India. We assessed 108 mother-child dyads and found that a one-unit increase in community stigma fear decreased child CD4 count by 352 cells $(95 \% \mathrm{CI}=-603$, - 102), highlighting the need to develop a better understanding of the consequences of HIV-related stigma on the compounded burden of care in households where mother and child both live with HIV.
\end{abstract}

Keywords Maternal HIV stigma $\cdot$ Discrimination $\cdot$ Seroconcordant $\cdot$ Child CD4

\section{Introduction}

\section{HIV Epidemic Among Children and Women}

Globally, an estimated 3 million children ( $\leq 19$ years) are living with HIV [1]; In India, this figure is approximately 120,000, the highest number reported for South Asia [1]. The primary mode of pediatric HIV transmission in resource-limited settings is perinatal transmission, from a mother living with HIV to her child during pregnancy, delivery, or breastfeeding [2, 3]. Hence, the extent of pediatric HIV infection is directly linked to the epidemiology of infection among women of reproductive age [4].

Biological vulnerabilities [5, 6], social norms, gender inequality [7], and cultural taboos about sexuality intersect to create structured disadvantages that lead to serious health

Valerie PhamDo

ValerieP@uci.edu

1 Sue \& Bill Gross School of Nursing, University of California, Irvine, CA, USA

2 Center for AIDS Prevention Studies, Department of Medicine, University of California, San Francisco, CA, USA

3 Division of Medical Informatics, St. John's Research Institute, Bangalore, India

4 Department of Medicine, All India Institute of Medical Sciences, New Delhi, India implications for women, obstructing the ability of female children and women to safeguard their reproductive health $[8,9]$. Structural inequalities [7], complicated by power structure and social hierarchy, lead to barriers that limit access to healthcare and make India's children and women disproportionately at risk for HIV infection [10,11]. Studies have shown that HIV stigma and discrimination adversely impact the physical, mental, and social well-being of women living with HIV, leading to an internalization of that stigma (i.e., acceptance of damaging self-image and fear of discrimination from HIV serostatus disclosure) [12]. Despite much progress in HIV research and treatment that make viral suppression possible for people living with HIV (PLWH), HIV stigma remains a major cause of physical, psychological, and social damage for PLWH, particularly for women living with HIV (WLWH) [13].

\section{HIV and Stigma}

HIV stigma has "social and moralistic connotations" [14] that involve negative attitudes, preconceived ideas, and undesirable beliefs about PLWH, often due to the tendency to blame PLWH for their infections; it is the prejudice that comes with categorizing an individual as part of a group that is deemed to be socially unwanted [15]. Current research [16] shows the main drivers of HIV stigma are pre-existing prejudices towards key populations at higher risk of HIV infection, such as people who inject drugs, transactional 
sex workers, inmates, transgender individuals, and men who have sex with men. Additional factors [16, 17] include misconceptions about casual transmissions, lack of personal experiences with PLWH, irrational fear of infection, and blame. While HIV continues to be a highly scorned illness [18] and the stigma associated with HIV continues to be a public health challenge globally, the impact of HIV-related stigma is worse in settings where HIV-related discrimination is gendered in nature. In their 2001 landmark study of HIV and AIDS in India, Bharat et al. [17] reported the neglect and maltreatment of WLWH by their spouses and in-laws. Specifically, Bharat and colleagues reported that WLWH were less likely than men to seek testing, received poorer quality care than their husbands, more likely to take care of their seropositive husbands, and often blamed for their husbands' infection by not controlling their husbands' extramarital desires.

HIV stigma has multiple behavioral consequences for PLWH [19]. Fear of stigma leads to care delays, negatively impacting disease management, and adversely affecting health outcomes [20-24]. Specifically, in India, HIV-related stigma is found to be associated with care seeking delays, both directly (i.e., when an individual chooses to not seek care for fear of mistreatment by healthcare staff) and indirectly (e.g., when an individual chooses to not disclose HIV status to family and consequently is unable to seek financial help for medical expenses) [22]. In India, the association between internalized stigma and low treatment adherence, and the association between internalized stigma and low quality of life were mediated by lack of disclosure and social support $[25,26]$. In terms of psychological challenges, it is well documented that stigma affects the emotional wellbeing and mental health of PLWH [27-29]. A systematic review and meta-analyses of the global literature published between 1996 and 2013 confirmed significant associations between HIV-related stigma and higher rates of depression, lower social support, lower usage of health and social services, and lower levels of adherence to antiretroviral treatment; these associations held up irrespective of cultural identity, sexual orientation, and sexual risk behaviors [30].

Stigma takes a multifaceted toll on the physical and psychological health of the maternal figure that, in turn, may lead to negative ramifications for the child [31-35]. Therefore, understanding the relationship between mothers' perceived HIV-related stigma and the health among their children is crucial [36], especially when both mother and child live with HIV, which may compound consequences of HIV-related stigma. In India, maternalchild HIV research is focused primarily on prevention of mother-to-child transmission [37], with few studies exploring mother and/or caregiver-child dyads outside the context of transmission prevention [38], and even fewer studies investigating mother-child HIV seroconcordant dyads
[39]. Borrowed from epidemiological studies regarding HIV transmission risk in intimate relationships [40] where seroconcordance describes relationships where couples are both HIV positive, we extend the concept of seroconcordance beyond intimate couples to include HIV-positive mother-child dyads. While there is a growing body of evidence regarding the role of HIV stigma on the health of WLWH, not much is known whether the same barriers that prevent a mother from accessing healthcare also impact her HIV infected child.

To our knowledge, no other published study has explored how maternal HIV-related stigma is associated with the CD4 count of children living with perinatallyacquired HIV (CLWPH) in low- and middle-income countries. While the multidimensional adverse consequences of HIV-related stigma on mothers are well-documented, the present paper explores outcomes among their children. In this present study, we sought to explore the seroconcordant dyad, in the context of whether different types of maternal HIV-related stigmas correlate with the child's immune function, expressed as CD4 count.

\section{Methods}

\section{Design and Sample}

This cross-sectional secondary analysis used data from a quasi-experimental trial funded by the National Institute of Mental Health (R01MH098728) that investigated the impact of a nurse-led ASHA (Accredited Social Health Activist)-supported behavioral and nutritional intervention among WLWH in rural Nellore and Prakasam, India between April 2014 and November 2016 [41, 42]. Flyerbased recruitment was utilized to engage participants from 16 community health centers and primary health clinics.

The parent study enrolled 600 WLWH between 18 to 50 years of age, diagnosed with HIV, receiving treatment for at least three months prior, have CD4 T-cell counts $>100$ cells $/ \mathrm{mm}^{3}$, and have a child between 3 to 8 living with them. If there were more than one child, only the eldest child was included in the parent study. Women who previously participated in the ASHA-Life pilot study were excluded. Data were collected by trained ASHAs during face-to-face interviews using a baseline questionnaire. Blood samples were collected for CD4 count determination. Full study details, including design, sample, setting, and procedures were previously described elsewhere $[41,42]$. For this present study, the sample included only seroconcordant dyads, where mother and child must both be diagnosed with HIV, reducing the parent study of 600 to a subsample of 109 mother-child dyads. 


\section{Measures}

A baseline questionnaire collected maternal sociodemographic information, CD4 cell counts of mother and child, and mother's HIV-related stigma variables. Sociodemographic factors collected from mothers included age, residence (Nellore or Prakasam), marital status (married, separated/ divorced, or widowed), number of children, gender of children, age of children, monthly household income (500-1200 rupees, 1500-2300 rupees, or 2400-3200 rupees), religion (Hindu, Muslim, or Christian), and educational attainment (none, $1-9$ years, or $\geq 10$ years). CD4 cell counts from mother and child were collected using flow cytometry. Blood samples were sent to the Nellore District Hospital diagnostic laboratory and the Act Diff Coulter Analyzer was used for CD4 determination [41, 42]. The absolute numbers of $\mathrm{CD} 4$ cells were obtained by multiplying percent CD4 by total white blood cell count [41, 42]. The outcome of interest for this secondary analysis was the CD4 count of CLWPH, predicted by maternal HIV stigma variables, discussed below.

\section{HIV-Related Stigma Variables}

Stigma variables measured included mother's stigma fears (fear of stigmatization upon HIV status disclosure to different social groups), stigma-avoidant coping, enacted stigma, internalized stigma, and vicarious [43] stigma. The scales used in the questionnaire were adapted to fit the current sample. For each stigma measure, a mean scale score was calculated for each category, except for enacted stigma, in which the total index score was constructed by calculating the sum of responses. Cronbach's alpha for each scale was calculated based on 109 dyads in this analysis.

\section{Stigma Fears}

Developed and previously used in India [26], this instrument used five subscales (family, friends, healthcare workers, coworkers, and community) to assess the degree (very worried, somewhat worried, a little worried, or not at all worried) of fear of discrimination/stigmatization upon HIV serostatus disclosure to social groups. For this study, we omitted the work subscale from further analysis, as $100 \%$ of our sample indicated "not applicable" to the last half of the scale items (withholding of promotions, forced relocation, mental harassment, and forced voluntary retirement).

Family This 6-item subscale measured the degree of worry of consequences driven by stigmatization upon HIV/AIDS status disclosure to family, such as physical abuse, verbal abuse/humiliation, family members keeping their distance, rejection by family, forced to leave the family home, and denial of property rights/inheritance of property. Previously a 7-item scale, this instrument was reduced to 6 items by omitting fear of divorce, as $56 \%$ of our sample was not married. Cronbach's alpha was 0.59 for the full 7 -item scale but improved to 0.80 after removing the irrelevant item.

Friends This 6-item subscale asked mothers to rate their degree of worry of the following stigma consequences upon status disclosure to friends, such as rejection, labeled an "HIV/AIDS patient," indirect taunts/humiliation in front of others, worried about friends divulging mother's HIV status to others, verbal abuse/humiliation, and accused of immoral behavior. Reliability of this scale was 0.86 .

Healthcare Workers This 5-item subscale asked mothers to rate their degree of worry of the following discriminatory consequences upon HIV/AIDS status disclosure to health care workers, such as health care workers treating PLWH worse than other patients, labelled an "AIDS patient," verbal abuse/humiliation, negligence in treatment, and health care workers taking unnecessary precautions (e.g., wearing a mask, double gloves) when caring for PLWH. Reliability of this scale was 0.80 .

Community This 12-item subscale, henceforth referred as "community stigma fear," measured mother's degree of worry of stigmatizing consequences upon HIV status disclosure to community members, such as expulsion from home by community members/leader, avoidance at social functions, avoidance at religious functions, labelled an "AIDS patient," physical abuse, verbal abuse/humiliation, forceful eviction from the main village, forced funeral services on the outskirts of the village or community, denial of proper funeral rites, denial of school for her children, and siblings or children not able to find an alliance for marriage. Internal consistency for this scale was 0.90 .

\section{Stigma-Avoidant Coping}

Stigma-avoidant coping was measured using a 9-item "disclosure avoidance" [43] questionnaire to assess the frequency (never, rarely, sometimes, or often) of coping behaviors PLWH use to conceal their HIV/AIDS diagnosis, such as describing their HIV/AIDS diagnosis as another disease, making up reasons for medical visits, using medi$\mathrm{cal} /$ pharmacy services outside the local village/community, concealing HIV/AIDS serostatus from health care workers, not taking or hiding ART medications in the presence of others, and avoiding status disclosure to family and friends to prevent them from telling others. Internal consistency for this scale was 0.87 . 


\section{Enacted Stigma}

Developed by Ekstrand et al. [21] for an Indian PLWH cohort and modified to fit our population [18, 22, 23], this variable measured overt acts of discrimination using a 10-item scale designed to capture specific discriminatory acts mothers experienced due to their HIV infection [44]. Mothers responded in a yes/no format to whether they experienced overt acts of discrimination, such as forced to move out of their home, asked to not touch or care for children, looked at differently, threatened physically, told not to share food/utensils with family, and denied medical care/hospital services. Internal consistency for this scale was 0.73 .

\section{Internalized Stigma}

Internalized stigma describes when a person living with HIV absorbs negative cultural beliefs, feelings, or thoughts about PLWH, leading to feelings of shame, fear of disclosure, isolation, and despair [45]. Specific to our population $[21,29]$, this subscale gauged the degree to which mothers believed they deserved to be shunned or shamed based on their HIV/AIDS diagnosis [43]. Modified from a 10-item scale for PLWH in India [46], our 8-item instrument asked mothers to rate the extent (not at all, a little, a fair amount, or a great deal) they feel they should avoid the following scenarios as a person with HIV/AIDS: holding an infant, feeding children, sharing dinnerware, cooking, and visiting others. The next three items pertain to the extent they agree with the following scenarios: brought shame to the family, paying for karma or sin, and feeling disgusting. Two items (diagnosed with HIV/AIDS because of wrong behaviors and feeling guilty about having HIV/AIDS) were eliminated for low correlation. Cronbach's alpha for our modified 8-item scale was 0.81 .

\section{Vicarious Stigma}

Based on the observational learning literature, vicarious stigma [43] describes a change in behavior after witnessing or hearing of consequences happening to others, even without personal experience [47]. This 10-item scale asked mothers how often (never, rarely, sometimes, or frequently) they heard stories about the mistreatment of PLWH, such as PLWH forced by family members to leave their home, ostracization by the village/community, family avoiding or refusing care of PLWH, denial of hospital services, mistreatment by hospital workers due to positive HIV serostatus, and hospital staff making PLWH's infection publicly known by marking HIV/AIDS on their medical records. Reliability for this scale was 0.91 .

\section{Statistical Analysis}

The overall purpose of this analysis was to determine the association between maternal HIV stigma and the CD4 count of children living with perinatally-acquired HIV. We used linear regression to investigate whether mother's fear of being stigmatized upon status disclosure to different social groups, stigma-avoidant coping, enacted stigma, internalized stigma, and vicarious stigma were correlated with her child's CD4 count. Characteristics of mother participants considered for possible confounding were age, marital status, number of children, income, CD4 count, religion, and educational attainment. Given that our sample size $(n=109)$ did not allow for control of all demographic variables, only variables associated with the outcome in bivariate models with p-value $<0.20$ were included in the final model. Maternal CD4 count and child BMI were not included in the final model to prevent over-adjustment bias [48]. We omitted maternal CD4 count and child BMI, as they could be mediators of the association between maternal HIV stigma and child CD4 count. Given the cross-sectional study design, we could not determine the temporality between these variables.

Using univariate frequency distribution methods, descriptive analysis was conducted for all relevant categorical demographic variables and possible correlates. A correlation matrix was created for pair-wise comparison between each variable. To analyze the relationship between child CD4 count and maternal HIV stigma correlates, linear regression analysis was conducted. Initial base model building included all HIV-related stigma variables, regardless of p-value. Starting with the set of stigma fears, each stigma fear subscale was added into the model one at a time. All stigma variables were analyzed as continuous variables. To control for confounding, additional variables (religion and educational attainment) were added to the full model because their $p$-values $(<0.2)$ were significant in the univariate analysis. Dummy coded variables were religion and educational attainment. The final model was verified for normality of residuals, multicollinearity, and heteroskedasticity. To estimate the internal consistency reliability of the stigma measures, Cronbach's alpha was utilized. All analyses were conducted in STATA 15.0. The standard used for statistical significance was a 2-tailed $p<0.05$.

\section{Results}

Tables 1 and 2 contain descriptive statistics for 109 dyads, after dropping dyads without seroconcordant diagnoses from the parent sample. Mothers were between 21 and 48 years of age, but the majority (56.9\%) were between 31 and 40 $(\mathrm{M}=33, \mathrm{SD}=6.02)$. They had an average $\mathrm{CD} 4$ count of 459 cells $/ \mathrm{mL}$. The majority ( $88 \%$ ) resided in Nellore with 
Table 1 Characteristics of mothers and children living with HIV/AIDS $(n=109)$

\begin{tabular}{|c|c|c|c|c|c|}
\hline Mother's characteristic & Mean (SD) or n (\%) & $\begin{array}{l}\text { Child's CD4 count } \\
\text { Mean (Std. Dev.) }\end{array}$ & Pearson's coef $r$ & Test statistic & p-value \\
\hline \multicolumn{4}{|l|}{ Residence } & \multirow[t]{3}{*}{$t$-value $=0.23$} & \multirow[t]{3}{*}{0.816} \\
\hline Nellore & $96(88.1 \%)$ & $767(289.4)$ & & & \\
\hline Prakasam & $13(11.9 \%)$ & $748(115.8)$ & & & \\
\hline \multicolumn{4}{|l|}{ Age } & \multirow[t]{4}{*}{ F-value $=1.31$} & \multirow[t]{4}{*}{0.274} \\
\hline $21-30$ & $38(34.9 \%)$ & $817(321.4)$ & & & \\
\hline $31-40$ & $62(56.9 \%)$ & $728(253.4)$ & & & \\
\hline $41-50$ & $9(8.26 \%)$ & $794(152.5)$ & & & \\
\hline \multicolumn{4}{|l|}{ Marital status } & \multirow[t]{4}{*}{ F-value $=0.03$} & \multirow[t]{4}{*}{0.971} \\
\hline Married & $47(43.1 \%)$ & $770(273.9)$ & & & \\
\hline Divorced/separated & $8(7.3) \%$ & $773(414.8)$ & & & \\
\hline Widowed & $54(49.5 \%)$ & $758(255.5)$ & & & \\
\hline \multicolumn{4}{|l|}{ Number of children } & \multirow[t]{4}{*}{ F-value $=0.58$} & \multirow[t]{4}{*}{0.559} \\
\hline 1 & $31(28.4 \%)$ & $782(328.5)$ & & & \\
\hline 2 & $60(55.1 \%)$ & $774(238.5)$ & & & \\
\hline 3 & $18(16.5 \%)$ & $701(290.8)$ & & & \\
\hline \multicolumn{4}{|c|}{ Monthly household income (rupees) } & \multirow[t]{4}{*}{ F-value $=1.06$} & \multirow[t]{4}{*}{0.349} \\
\hline $500-1200$ & $17(15.6 \%)$ & $679(310.1)$ & & & \\
\hline $1500-2300$ & $55(50.5 \%)$ & $771(318.1)$ & & & \\
\hline $2400-3200$ & $37(33.9 \%)$ & $794(163.2)$ & & & \\
\hline \multicolumn{4}{|l|}{ Religion } & \multirow[t]{4}{*}{ F-value $=3.47$} & \multirow[t]{4}{*}{0.0348} \\
\hline Hindu & $74(67.9 \%)$ & $724(257.7)$ & & & \\
\hline Muslim & $9(8.3 \%)$ & $751(212.1)$ & & & \\
\hline Christian & $26(23.9 \%)$ & $885(310.8)$ & & & \\
\hline \multicolumn{4}{|l|}{ Educational attainment } & \multirow[t]{4}{*}{ F-value $=1.77$} & \multirow[t]{4}{*}{0.176} \\
\hline None & $50(45.9 \%)$ & $729(298.5)$ & & & \\
\hline $1-9$ years & $47(43.1 \%)$ & $767(245.2)$ & & & \\
\hline$\geq 10$ years & $12(11.0 \%)$ & $894(256.8)$ & & & \\
\hline CD4 count $($ cells/mL) & $459(286.5)$ & & 0.2135 & $t$-value $=2.26$ & 0.026 \\
\hline Child's characteristic & Mean (SD) or n (\%) & $\begin{array}{l}\text { Child's CD4 count } \\
\text { Mean (Std. Dev.) }\end{array}$ & Pearson's coef $r$ & Test statistic & p-value \\
\hline \multicolumn{3}{|l|}{ Gender } & & \multirow[t]{3}{*}{$\mathrm{t}$-value $=-0.85$} & \multirow[t]{3}{*}{0.4} \\
\hline Male & $55(50.5 \%)$ & $742(262)$ & & & \\
\hline Female & $54(49.5 \%)$ & $787(286.8)$ & & & \\
\hline \multicolumn{3}{|l|}{ Age } & & $\mathrm{t}$-value $=0.84$ & 0.40 \\
\hline $3-5$ & $15(13.8 \%)$ & $820(328.1)$ & & & \\
\hline $6-8$ & $94(86.2 \%)$ & $756(265.6)$ & & & \\
\hline$B M I$ & $15(2.25)$ & & 0.2016 & $\mathrm{t}$-value $=2.13$ & 0.036 \\
\hline
\end{tabular}

the following civil statuses: $49.5 \%$ widowed, $43.1 \%$ married, and $7.3 \%$ divorced/separated. In terms of income, the average monthly household income ranged from 500 to 3200 Indian rupees (i.e., currency conversion of $\sim \$ 6.73$ to $\sim$ \$43.06 US dollars) $(\mathrm{M}=1998$ rupees, $\mathrm{SD}=695.62)$, and half $(50.5 \%)$ reported a monthly household income between 1500 and 2300 rupees. In terms of religious affiliation, most mothers identified as belonging to Hindu faith $(67.9 \%)$. As for educational attainment, $45.9 \%$ of mothers reported having no formal education, $43.1 \%$ reported having $1-9$ years of education, while $11 \%$ had $\geq 10$ years of educational attainment.

More than half $(55.1 \%)$ of mother participants had two children. Their children's ages ranged from 3 to 8 years, but $86 \%$ were between ages 6 and 8 . Of the total number of children diagnosed with HIV, 55 were male and 54 were female. Their children's CD4 count (cells $/ \mathrm{mm}^{3}$ ) ranged from 258 to $1500(\mathrm{M}=764, \mathrm{SD}=274.18)$. 
Table 2 Stigma variables of mothers living with HIV $(\mathrm{n}=109)$

\begin{tabular}{llrrc}
\hline Stigma scale & Mean & \multicolumn{1}{l}{ Coef $\mathrm{r}$} & $t$-value & $p$-value \\
\hline Stigma fear-family* & 2.49 & 0.0458 & 0.47 & 0.638 \\
Stigma fear-friends & 2.89 & -0.1551 & -1.62 & 0.107 \\
Stigma fear-healthcare & 2.8 & -0.0796 & -0.83 & 0.410 \\
Stigma fear-community & 2.77 & -0.1594 & -1.67 & 0.098 \\
Stigma-avoidant coping & 2.37 & -0.0011 & -0.01 & 0.991 \\
Enacted stigma & 7.74 & 0.0860 & 0.89 & 0.374 \\
Internalized stigma & 2.76 & 0.0268 & 0.28 & 0.782 \\
Vicarious stigma & 2.42 & 0.0689 & 0.71 & 0.477 \\
\hline
\end{tabular}

*108 observations

In the unadjusted model, our regression analysis revealed that mother's stigma-avoidant coping, vicarious stigma, internalized stigma, and enacted stigma were not associated with her child's CD4 count. Among the stigma fears, the only variable of statistical significance was mother's community stigma fear. Mother's community stigma fear was negatively correlated with child CD4 count, where for each one-unit increase in mother's community stigma fear, her child's CD4 count decreased by 403 cells $(95 \% \mathrm{CI}=-652$, $-155 ; t$-value $=-3.22 ; \mathrm{p}=0.002$ ).

To control for confounding, religion and educational attainment were added to the final model because their $\mathrm{p}$-values $(<0.2)$ were significant in the univariate analysis. In the adjusted model (Table 3), mother's community stigma fear remained predictive of child CD4 count. However, we also found an association between maternal religion and child
CD4 count. Specifically, mother's Christian faith was associated with a higher CD4 count in her child.

\section{Association Between Community Stigma Fear and Child CD4 Count}

Although data were retrieved for 109 seroconcordant mother-child dyads, our regression analysis $(n=108)$ reported data for one less dyad due to missing data for mother's family stigma fear. We examined the association between maternal HIV-related stigma variables and child CD4 as our main objective for this analysis and our adjusted model demonstrated that mother's community stigma fear was correlated with child CD4 count. Mother's community stigma fear remained predictive of child CD4 count, demonstrating a negative relationship where for every one-unit increase in mother's community stigma fear, her child's CD4 count decreased by 352 cells $(95 \% \mathrm{CI}=-603,-102$; $t$-value $=-2.79 ; \mathrm{p}=0.006)$ in the adjusted model.

\section{Discussion}

The literature demonstrating an association between HIVrelated stigma and health outcomes has grown significantly [30], and our study further adds to the body of evidence on the association between stigma and health by exploring the correlation between maternal HIV-related stigma and children's CD4 in rural Indian seroconcordant mother-child dyads, revealing at least one possible relationship. We found

Table 3 Unadjusted and adjusted models $(\mathrm{n}=108)$

\begin{tabular}{|c|c|c|c|c|c|c|c|c|c|c|}
\hline \multirow{3}{*}{$\begin{array}{l}\text { Variable } \\
\text { Stigma fear }\end{array}$} & \multicolumn{5}{|c|}{ Base model } & \multicolumn{5}{|c|}{ Full model } \\
\hline & \multirow[t]{2}{*}{$B$ Coef } & \multirow[t]{2}{*}{$t$-value } & \multirow[t]{2}{*}{$p$-value } & \multicolumn{2}{|c|}{ [95\% conf. interval] } & \multirow[t]{2}{*}{$B$ Coef } & \multirow[t]{2}{*}{$t$-value } & \multirow[t]{2}{*}{$p$-value } & \multicolumn{2}{|c|}{ [95\% conf. interval] } \\
\hline & & & & & & & & & & \\
\hline Family & 49 & 0.71 & 0.479 & -88.083 & 186.511 & 94 & 1.29 & 0.200 & -50.464 & 238.497 \\
\hline Friends & -74 & -0.63 & 0.530 & -306.858 & 159.043 & -81 & -0.70 & 0.487 & -311.406 & 149.384 \\
\hline Healthcare workers & 74 & 0.68 & 0.501 & -143.487 & 291.790 & 48 & 0.44 & 0.659 & -168.439 & 265 \\
\hline Community & -403 & -3.22 & 0.002 & -651.752 & -155.159 & -352 & -2.79 & 0.006 & -602.798 & -102.088 \\
\hline Stigma-avoidant coping & 54 & 0.57 & 0.568 & -131.971 & 239.312 & 52 & 0.55 & 0.582 & -133.665 & 236.740 \\
\hline Enacted stigma & 28 & 1.38 & 0.170 & -12.343 & 68.925 & 14 & 0.66 & 0.511 & -28.554 & 57.025 \\
\hline Internalized stigma & 49 & 0.41 & 0.686 & -189.077 & 286.375 & 40 & 0.34 & 0.733 & -194.167 & 275.093 \\
\hline Vicarious stigma & 75 & 1.00 & 0.320 & -74.060 & 224.224 & 80 & 1.07 & 0.286 & -68.176 & 228.358 \\
\hline \multicolumn{11}{|l|}{ Religion } \\
\hline Hindu & & & & & & Ref & & & & \\
\hline Muslim & & & & & & 118 & 1.18 & 0.240 & -80.032 & 316.160 \\
\hline Christian & & & & & & 125 & 1.99 & 0.049 & 0.487 & 249.939 \\
\hline \multicolumn{11}{|l|}{ Education } \\
\hline None & & & & & & Ref & & & & \\
\hline $1-9$ years & & & & & & 22 & 0.40 & 0.692 & -87.897 & 131.861 \\
\hline$\geq 10$ years & & & & & & 126 & 1.45 & 0.151 & -46.924 & 298.977 \\
\hline
\end{tabular}


a significant negative correlation between community stigma fear and child CD4 count. This finding is consistent with prior studies that show multiple harmful effects of HIV stigma on the health of people living with HIV. Alternatively, our finding is consistent with other literature, suggesting that perhaps having a healthier child shields the mother from fear that she will be rejected by her community. For instance, children living with HIV receive access to health care through parental figures; their diagnostic procedures, medical appointments, and treatment adherence depend on family members' access to health care services [49]. Our results are in accordance with a previous study [50], that the real or imagined fear may deter mothers from seeking community services and support that would be beneficial to help both mother's and child's HIV prognoses. In studies on stigma and care seeking behaviors in Asia [51] and globally [52], stigma has been correlated with barriers to care. We speculate that community stigma fear is correlated with the underutilization of resources and barriers to seeking help, demonstrated by a lower child CD4 count.

In contrast to our finding, Chandy et al. [53] studied a comparable population, WLWH in South India, and found that women who were afraid they would experience community-level stigma were more likely to seek care for their health. However, unlike the Chandy study, we did not look at mothers' engagement in care, but at their children's health. It is possible that community-level HIV stigma may have differential impact on seroconcordant mother-child dyads among a broader population of WLWH. For example, fear of blame for the child's HIV status may increase the harmful effect of community-level HIV stigma on children of women living with HIV. Additional research is needed to elucidate the complex dynamics that affect the relationship between community-level HIV stigma and children's health.

\section{Limitations}

There were several limitations in our study. The primary limitation is the cross-sectional nature of our study that prevents us from drawing any conclusions regarding causality. Given our study design, it is unknown whether child health influences mother's stigma fear or mother's stigma fear influences care seeking and child health. For example, mothers of children who are healthy may be less afraid of community stigma. Longitudinal studies are needed to improve our understanding of whether a causal relationship exists between these variables. Of note, the stigma measures only assessed mother's fear of how she would be treated if her HIV status was disclosed. The measures did not directly assess mother's fear of what would happen to her child if her child's HIV diagnosis was disclosed. It is possible that mother's stigma fear for herself is different than her fear for her child. Moreover, our study investigated a very specific rural community; therefore, results may not generalize to mothers and children in more urban settings. Lastly, the fact that all children were provided with antiviral therapy as standard practice in India could have affected our correlation estimate. Our results cannot be generalized to families with children who are not on ART as standard practice.

\section{Conclusions}

Our exploratory analysis suggests that mothers who are afraid of stigma from community members are likely to have children with lower CD4 counts. Stronger study designs are needed to improve our understanding of the underlying mechanism for this difference and whether a causal relationship exists between these variables. We emphasize the need for future in-depth qualitative studies and longitudinal quantitative studies that seek to understand the underlying mechanisms whereby stigma impacts clinical outcomes in children. Our findings highlight the need to understand stigma on a more granular level, to better understand the impact of HIV-related stigma on the compounded burden of care in a seroconcordant household where mother and child both live with HIV.

Acknowledgements We are thankful to the study participants who made this study possible. This work was supported by the National Institute of Mental Health of the National Institutes of Health through Grant R01MH098728.

Author Contributions VP conceived of the presented idea and drafted the manuscript. VP, SS, AN, and ME interpreted the results and SS verified the analytical methods. All authors provided critical feedback and helped shape the final manuscript.

Funding This work was supported by the National Institute of Mental Health of the National Institutes of Health through Grant R01MH098728 (PI A. Nyamathi).

Data Availability De-identified data will be shared upon receipt of a completed data request form.

Code Availability Study code will be shared upon formal receipt of a completed request form.

\section{Declarations}

Conflict of interest The authors declare that they have no conflict of interest.

Ethical Approval All procedures in this study were performed in accordance with the ethical standards of the 1964 Helsinki declaration and its later amendments. This study was approved by the University of California Irvine Institutional Review Board and the Ministry of Health Research Ethics Committee in India. 
Consent to Participate Informed consent was obtained from all individual participants included in the study.

Consent for Publication Not applicable.

Informed Consent Informed consent was obtained from all individual participants included in the study.

Open Access This article is licensed under a Creative Commons Attribution 4.0 International License, which permits use, sharing, adaptation, distribution and reproduction in any medium or format, as long as you give appropriate credit to the original author(s) and the source, provide a link to the Creative Commons licence, and indicate if changes were made. The images or other third party material in this article are included in the article's Creative Commons licence, unless indicated otherwise in a credit line to the material. If material is not included in the article's Creative Commons licence and your intended use is not permitted by statutory regulation or exceeds the permitted use, you will need to obtain permission directly from the copyright holder. To view a copy of this licence, visit http://creativecommons.org/licenses/by/4.0/.

\section{References}

1. UNICEF. Children, HIV and AIDS: the world today and in 2030 [Internet]. 2018. Available from https://data.unicef.org/resources/ children-hiv-and-aids-2030/. Accessed 4 March 2020

2. World Health Organization. Treatment of children living with HIV [Internet]. n.d. Available from https://www.who.int/hiv/topics/paediatric/hiv-paediatric-infopage/en/. Accessed 1 Feb 2020

3. NIH: National Institute of Allergy and Infectious Diseases. Prevention of perinatal HIV transmission [Internet]. 2017. Available from https://www.niaid.nih.gov/diseases-conditions/preventionperinatal-transmission. Accessed 4 Jan 2020

4. Embree J. The impact of HIV/AIDS on children in developing countries. Paediatr Child Health. 2005;10(5):261-3.

5. Yi TJ, Shannon B, Prodger J, McKinnon L, Kaul R. Genital immunology and HIV susceptibility in young women. Am J Reprod Immunol. 2013;69(Suppl. 1):74-9.

6. Dellar RC, Dlamini S, Karim QA. Adolescent girls and young women: key populations for HIV epidemic control. J Int AIDS Soc. 2015;18(2 Suppl 1):19408.

7. Heise L, Greene ME, Opper N, Stavropoulou M, Harper $\mathrm{C}$, Nascimento $\mathrm{M}$, et al. Gender inequality and restrictive gender norms: framing the challenges to health. Lancet. 2019;393(10189):2440-54.

8. Campbell CA. Women, families and HIV/AIDS: a sociological perspective on the epidemic in America. Cambridge: Cambridge University Press; 1999.

9. UNAIDS. Women and HIV - A spotlight on adolescent girls and young women [Internet]. 2019. Available from https://www. unaids.org/sites/default/files/media_asset/2019_women-and-hiv_ en.pdf. Accessed 4 March 2020

10. Mothi SN, Lala MM, Tappuni AR. HIV/AIDS in women and children in India. Oral Dis. 2016;22(Suppl. 1):19-24.

11. Bharat S. Facing the challenge: household responses to HIV/AIDS in Mumbai, India. AIDS Care. 1999;11(1):31-44.

12. Paudel V, Baral KP. Women living with HIV/AIDS (WLHA), battling stigma, discrimination and denial and the role of support groups as a coping strategy: a review of literature. Reprod Health. 2015;2(12):53.
13. Ho S-S, Holloway A. The impact of HIV-related stigma on the lives of HIV-positive women: an integrated literature review. J Clin Nurs. 2016;25(1-2):8-19.

14. Islam MS, Minichiello V, Scott J. Children living in HIV families: a review. J Child Adolesc Behav. 2014; 2(5).

15. Centers for Disease Control and Prevention (CDC). Dealing with stigma and discrimination [Internet]. 2019. Available from https:// www.cdc.gov/hiv/basics/livingwithhiv/stigma-discrimination. html. Accessed 4 March 2020

16. UNAIDS. Reduction of HIV-related stigma and discrimination. Guidance Note. [Internet]. 2014. Available from https://www. unaids.org/en/resources/documents/2014/ReductionofHIV-relat edstigmaanddiscrimination. Accessed 1 March 2020

17. Bharat S, Aggleton P, Tyrer P. India: HIV and AIDS-related discrimination, stigmatization and Denial [Internet]. Geneva, Switzerland: UNAIDS; 2001. Available from https://public.ebookcentr al.proquest.com/choice/publicfullrecord.aspx? $\mathrm{p}=5301117$.

18. Chambers LA, Rueda S, Baker DN, Wilson MG, Deutsch R, Raeifar E, et al. Stigma, HIV and health: a qualitative synthesis. BMC Public Health. 2015;15(1):848.

19. Ekstrand ML, Bharat S, Srinivasan K. HIV stigma is a barrier to achieving 90-90-90 in India. Lancet HIV. 2018;5(10):e543-5.

20. Chesney MA, Smith AW. Critical delays in HIV testing and care: the potential role of stigma. Am Behav Sci. 1999;42(7):1162-74.

21. Ekstrand ML, Bharat S, Ramakrishna J, Heylen E. Blame, symbolic stigma and HIV misconceptions are associated with support for coercive measures in urban India. AIDS Behav. 2012;16(3):700-10

22. Steward WT, Bharat S, Ramakrishna J, Heylen E, Ekstrand ML. Stigma is associated with delays in seeking care among HIV-infected people in India. J Int Assoc Provid AIDS Care. 2013;12(2):103-9.

23. Kumar S, Mohanraj R, Rao D, Murray KR, Manhart LE. Positive coping strategies and HIV-related stigma in south India. AIDS Patient Care STDs. 2015;29(3):157-63.

24. Rahangdale L, Banandur P, Sreenivas A, Turan JM, Washington $\mathrm{R}$, Cohen CR. Stigma as experienced by women accessing prevention of parent-to-child transmission of HIV services in Karnataka. India AIDS Care. 2010;22(7):836-42.

25. Nyamathi A, Ekstrand M, Heylen E, Ramakrishna P, Yadav K, Sinha S, et al. Relationships among adherence and physical and mental health among women living with HIV in rural India. AIDS Behav. 2018;22(3):867-76.

26. Ekstrand ML, Heylen E, Mazur A, Steward WT, Carpenter C, Yadav K, et al. The role of HIV stigma in ART adherence and quality of life among rural women living with HIV in India. AIDS Behav. 2018;22(12):3859-68.

27. Major B, O'Brien LT. The social psychology of stigma. Annu Rev Psychol. 2005;56(1):393-421.

28. Das S, Leibowitz GS. Mental health needs of people living with HIV/AIDS in India: a literature review. AIDS Care. 2011;23(4):417-25.

29. Steward WT, Chandy S, Singh G, Panicker ST, Osmand TA, Heylen E, et al. Depression is not an inevitable outcome of disclosure avoidance: HIV stigma and mental health in a cohort of HIVinfected individuals from southern India. Psychol Health Med. 2011;16(1):74-85.

30. Rueda S, Mitra S, Chen S, Gogolishvili D, Globerman J, Chambers L, et al. Examining the associations between HIV-related stigma and health outcomes in people living with HIV/AIDS: a series of meta-analyses. BMJ Open. 2016;6(7):e011453.

31. Chi P, Li X. Impact of parental HIV/AIDS on children's psychological well-being: a systematic review of global literature. AIDS Behav. 2013;17(7):2554-74. 
32. Sherr L, Cluver LD, Betancourt TS, Kellerman SE, Richter LM, Desmond C. Evidence of impact: health, psychological and social effects of adult HIV on children. AIDS. 2014;28(Suppl 3):S251-9.

33. Goldberg RE, Short SE. What do we know about children living with HIV-infected or AIDS-ill adults in Sub-Saharan Africa? A systematic review of the literature. AIDS Care. 2016;28(Suppl 2):130-41.

34. Domlyn AM, Jiang Y, Harrison S, Qiao S, Li X. Stigma and psychosocial wellbeing among children affected by parental HIV in China. AIDS Care. 2020;32(4):500-7.

35. Satyanarayana VA, Burroughs HR, Heylen E, Yadav K, Sinha S, Nyamathi AM, et al. Mental health of women living with HIV and its impact on child development in Andhra Pradesh, India. Vulnerable Child Youth Stud. 2021;22:1-13.

36. Murphy DA, Marelich WD, Armistead L, Herbeck DM, Payne DL. Anxiety/stress among mothers living with HIV: effects on parenting skills and child outcomes. AIDS Care. 2010;22(12):1449-58.

37. Darak S, Panditrao M, Parchure R, Kulkarni V, Kulkarni S, Janssen F. Systematic review of public health research on prevention of mother-to-child transmission of HIV in India with focus on provision and utilization of cascade of PMTCT services. BMC Public Health. 2012;2(12):320.

38. Gamarel KE, Kuo CC, Boyes ME, Cluver LD. The dyadic effects of HIV stigma on the mental health of children and their parents in South Africa. J HIVAIDS Soc Service. 2017;16(4):351-66.

39. Das A, Detels R, Afifi AA, Javanbakht M, Sorvillo FJ, Panda S. Health-related quality of life (HRQoL) and its correlates among community-recruited children living with HIV and uninfected children born to HIV-infected parents in West Bengal, India. Qual Life Res. 2017;26(8):2171-80.

40. Persson A, Newman CE, Hamilton M, Bryant J, Wallace J, Valentine K. Families living with blood-borne viruses: the case for extending the concept of "Serodiscordance." Interdiscip Perspect Infect Dis. 2017;18(2017):4352783.

41. Nyamathi AM, Carpenter CL, Ekstrand ML, Yadav K, Garfin DR, Muniz LC, et al. Randomized controlled trial of a communitybased intervention on HIV and nutritional outcomes at six months among women living with HIV/AIDS in rural India. AIDS. 2018;32(18):2727.

42. Nyamathi AM, Shin SS, Sinha S, Carpenter CL, Garfin DR, Ramakrishnan P, et al. Sustained effect of a community-based behavioral and nutrition intervention on HIV-related outcomes among women living with HIV in rural India: a quasi-experimental trial. J Acquir Immune Defic Syndr. 2019;81(4):429-38.

43. Steward WT, Herek GM, Ramakrishna J, Bharat S, Chandy S, Wrubel J, et al. HIV-related stigma: adapting a theoretical framework for use in India. Soc Sci Med. 2008;67(8):1225-35.
44. Nyamathi A, Hanson AY, Salem BE, Sinha S, Ganguly KK, Leake $\mathrm{B}$, et al. Impact of a rural village women (Asha) intervention on adherence to antiretroviral therapy in southern India. Nurs Res. 2012;61(5):353-62.

45. Centers for Disease Control and Prevention (CDC). Facts about HIV Stigma [Internet]. 2019. Available from https://www.cdc. gov/hiv/basics/hiv-stigma/index.html. Accessed 4 March 2020

46. Ekstrand ML, Ramakrishna J, Bharat S, Heylen E. Prevalence and drivers of HIV stigma among health providers in urban India: implications for interventions. J Int AIDS Soc. 2013;16(3 Suppl 2): 18717.

47. Nyamathi A, Ekstrand M, Zolt-Gilburne J, Ganguly K, Sinha S, Ramakrishnan P, et al. Correlates of stigma among rural Indian women living with HIV/AIDS. AIDS Behav. 2013;17(1):329-39.

48. Schisterman EF, Cole SR, Platt RW. Overadjustment bias and unnecessary adjustment in epidemiologic studies. Epidemiology. 2009;20(4):488-95.

49. Busza J, Simms V, Chikwari CD, Dauya E, Bandason T, Makamba $\mathrm{M}$, et al. "It is not possible to go inside and have a discussion": how fear of stigma affects delivery of community-based support for children's HIV care. AIDS Care. 2018;30(7):903-9.

50. Krauss BJ, Letteney S, Okoro CN. Why tell children: a synthesis of the global literature on reasons for disclosing or not disclosing an HIV diagnosis to children 12 and under. Front Public Health. 2016;8(4):181.

51. Koirala S, Deuba K, Nampaisan O, Marrone G, Ekström AM. Facilitators and barriers for retention in HIV care between testing and treatment in Asia-A study in Bangladesh, Indonesia, Lao, Nepal, Pakistan, Philippines and Vietnam. PLoS ONE. 2017;12(5):e0176914.

52. Johnson M, Samarina A, Xi H, Madruga JVR, Hocqueloux L, Loutfy M, et al. Barriers to access to care reported by women living with HIV across 27 countries. AIDS Care. 2015;27(10):1220-30.

53. Chandy S, Heylen E, Ravikumar BN, Ekstrand ML. Examining engagement in care of women living with HIV in South India. Health Care Women Int. 2019;26:1-14.

Publisher's Note Springer Nature remains neutral with regard to jurisdictional claims in published maps and institutional affiliations. 